\title{
The level of organisational identification amongst students at a post-merged South African university
}

\begin{tabular}{|c|c|}
\hline \multicolumn{2}{|c|}{$\begin{array}{l}\text { Authors: } \\
\text { Nadia Breytenbach }^{1} \\
\text { Michelle Renard }^{1} \\
\text { Robin J. Snelgar }\end{array}$} \\
\hline \multicolumn{2}{|c|}{$\begin{array}{l}\text { Affiliations: } \\
{ }^{1} \text { Industrial and Organisational } \\
\text { Psychology Department, } \\
\text { Nelson Mandela } \\
\text { Metropolitan University, } \\
\text { South Africa }\end{array}$} \\
\hline \multicolumn{2}{|c|}{$\begin{array}{l}\text { Correspondence to: } \\
\text { Michelle Renard }\end{array}$} \\
\hline \multicolumn{2}{|c|}{$\begin{array}{l}\text { Email: } \\
\text { michelle.renard@nmmu. } \\
\text { ac.za }\end{array}$} \\
\hline \multicolumn{2}{|c|}{$\begin{array}{l}\text { Postal address: } \\
\text { PO Box 77000, Nelson } \\
\text { Mandela Metropolitan } \\
\text { University, Port Elizabeth } \\
6031 \text {, South Africa }\end{array}$} \\
\hline \multicolumn{2}{|c|}{$\begin{array}{l}\text { Dates: } \\
\text { Received: } 02 \text { May } 2012 \\
\text { Accepted: } 29 \text { Jan. } 2013 \\
\text { Published: } 29 \text { Apr. } 2013\end{array}$} \\
\hline \multicolumn{2}{|c|}{$\begin{array}{l}\text { How to cite this article: } \\
\text { Breytenbach, N., Renard, } \\
\text { M., \& Snelgar, R.J. (2013). } \\
\text { The level of organisational } \\
\text { identification amongst } \\
\text { students at a post-merged } \\
\text { South African university. SA } \\
\text { Journal of Human Resource } \\
\text { Management/SA Tydskrif vir } \\
\text { Menslikehulpbronbestuur, } \\
\text { 11(1), Art. \#477, } 14 \text { pages. } \\
\text { http://dx.doi.org/10.4102/ } \\
\text { sajhrm.v11i1.477 }\end{array}$} \\
\hline \multicolumn{2}{|c|}{$\begin{array}{l}\text { Copyright: } \\
\text { C 2013. The Authors. } \\
\text { Licensee: AOSIS } \\
\text { OpenJournals. This wor } \\
\text { is licensed under the } \\
\text { Creative Commons } \\
\text { Attribution License. }\end{array}$} \\
\hline \multicolumn{2}{|l|}{ Read online: } \\
\hline 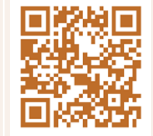 & $\begin{array}{l}\text { Scan this QR } \\
\text { code with your } \\
\text { smart phone or } \\
\text { mobile device } \\
\text { to read online. }\end{array}$ \\
\hline
\end{tabular}

Orientation: Organisational identification (OI) refers to individuals perceiving that they belong to and are one with their organisation. Limited research has been conducted on university students' levels of OI within the South African context.

Research purpose: The aim of the study was to determine the level of OI amongst students at a post-merged university in the Eastern Cape Province of South Africa.

Motivation for the study: Levels of OI amongst students at a post-merged university could be low, as a result of students not yet adopting the values of the merged university. Yet, no such study has been undertaken at this university since the merger.

Research design, approach and method: Mixed methods were used in this study, consisting of qualitative research $(N=16)$ for which focus group discussions were used, as well as quantitative research $(N=603)$ for which an online questionnaire was sent to the student sample.

Main findings: The level of OI amongst the students was found to be high. Furthermore, students' race, campus, university tenure and residence have a significant influence on students' levels of OI. Black students identified more with the university than other races and students who studied longer at this university had lower levels of OI. Residence students had a greater level of OI than those who stayed off-campus.

Practical/managerial implications: Students should be encouraged to adopt the core values of this university to ensure that OI levels increase. In order to improve OI, university management should implement action plans for those student segments who have exhibited low levels of OI.

Contribution/value-add: This research contributes to the current body of knowledge concerning OI which is under-researched within a post-merged university context.

\section{Introduction}

\section{Key focus of the study}

University students' performance has an impact on the economy of the country in which it is situated (Bloom, Canning \& Chan, 2005). For this reason, it is important for universities to deliver quality graduates. According to Taylor (2010), universities are one means by which organisations can be provided with the labour market they require to ensure future success. In order to provide such quality graduates, universities require motivated and engaged students (Griesel \& Parker, 2009). Research has shown that students' levels of pride towards their university affects their levels of motivation and engagement (Winn \& Green, 1998). These authors continued to state that by engaging students and simultaneously involving them in the decision-making of their education programmes, their level of pride towards the university can be enhanced. Through encouraging students to actively partake in their academic success, universities can instil pride in students towards their university. According to Bartels (2006), this sense of pride towards a group or institution is a result of organisational identification (OI).

Organisational identification is traditionally defined as the perception of oneness with, or belongingness to an organisation', where an employee recognises him or herself as a part of the organisation in which he or she works (Mael \& Ashforth, 1992, p. 104). OI, although initially conceptualised to refer to employees within organisations, can also be interpreted within the university context, because employees identify with their organisation in a similar way to how students identify with their university as an institution. Indeed, according to Bartels (2006), OI is not only important for 'profit organisations', but also for non-profit organisations, such as hospitals and universities. He states that non-profit organisations are becoming service orientated and further explains that universities, for example, need to take into account the student as a 
'customer that is affected by the organisation's actions' and who is evaluated on these organisational actions (Bartels, 2006, p. 2).

Kim, Chang and Ko (2010) state that because OI leads to a sense of belonging to an organisation, students with high levels of OI towards their university will form an emotional bond with the university. These authors go on to state that students are the future support system (alumni) of the university and research has shown that students who identify with their university are more likely to support the university in the future. For example, students who indentify with their university are more likely to donate to the university, become a lecturer or send their children to that specific university (Caboni \& Eiseman, 2003). The reason for this is because when students identify strongly with their university, the university's success reflects on them (Kim et al., 2010).

More importantly, these authors explained that by ensuring a high level of student identification with their university, students will be more willing to change their behaviour to suit the desired behaviour that is expected from the university's management. This can include students' behaviour toward their academic work, participation in university activities and their social behaviour. Students will be less likely to participate in activities or events that will harm the reputation of the university when identifying strongly with their university (Kim et al., 2010).

\section{Background and research purpose}

Based on the above understanding of OI, the researchers undertook the present study in order to ascertain the level of OI amongst students at a university in the Eastern Cape Province of South Africa. Owing to this university undergoing a merger between three different institutions in the last decade, it is likely that levels of OI will be low, as it is possible that students have not yet adopted the new values that the merged university have promoted in the last few years. This could possibly be the result of influence by parents and community members, who still refer to the university by its old name and might still focus on its old values or reputation. Certainly, from the perspective of academic staff members, it has been found that OI decreases in a post-merger environment (Beelen, 2007). If this is the case from a student perspective in the post-merged university under study, then such low levels of OI would need to be addressed by university management.

This study thus aims to investigate the level of OI amongst students at a post-merged university in South Africa. Particularly, it seeks to determine whether certain demographic characteristics influence the level of OI amongst students at this university. The literature review to follow will discuss OI in general, the importance of OI for students and the factors that need to be considered when dealing with students' levels of OI.

\section{Literature review}

\section{Organisational identification}

Tajfel and Turner (1979) were the first to introduce the concept of OI. These authors state that people classify all individuals, including themselves, into various groups. Beelen (2007) states that when individuals identify with a group, the group can have an influence on the self-esteem of the individual. Beelen (2007) further explains that when a group's norms influence the individual, they identify strongly with the group and become one with it. Foreman and Whetten (2002) agree by stating that individuals use the group to define themselves. To elaborate on this, Albert, Ashforth and Dutton (2000) explain that OI is a process that individuals go through not only to be a part of a group, but also to determine who they are personally.

Dutton, Dukerich and Harquail (1994, p. 39) explain that OI is a subgroup of social classification, which is defined as a process in which 'individuals define themselves through a sense of oneness' or identification with a particular group. According to Bartels (2006), these groups can include age, gender, race, sport teams and political movements. This author continues to state that when individuals identify with their particular group, they would defend their group when it is criticised by others.

Foreman and Whetten (2002, p. 1) raised the question as to why individuals or members identify with an organisation. According to these authors, identification occurs because of a 'cognitive comparison'. Members assess whether their values and beliefs 'fit' with those of the organisation (Foreman \& Whetten, 2002, p. 3) and this will either lead to a 'fit', which increases OI, or no 'fit', which will lead to a decrease in the strength of OI. Dutton et al. (1994), on the other hand, believe that each individual identifies differently with his or her organisation and that the image that is held of the organisation is unique, compared to those of other individuals. This 'identity comparison' between employees and their organisation (Foreman \& Whetten, 2002) can occur in two ways. Firstly, Asforth and Mael (1989) explain that the employees can evaluate their own identity relative to that of the organisation for which they work. Alternatively, they can compare their view of the organisation's current identity to what the members want the organisation's identity to be (Reger, Gustafson, Demarie \& Mullane, 1994).

Albert et al. (2000) state that identification provides an answer to a question that all individuals ask in their lives, namely who they are in relation to others. It is in each individual's nature to ask where he or she belongs and, for this reason, OI contributes towards such a sense of belonging (Albert et al., 2000) if he or she shares the same values as the organisation. Van Knippenberg and Sleebos (2006) explain that identification is therefore a reflection of the way in which individuals define themselves. 


\section{Importance of organisational identification for students and universities}

Universities should consider the benefits to them when managing students' levels of OI. For example, according to Porter, Hartman and Johnson (2011, p. 3), high levels of OI will lead to student behaviours that 'support, maintain, and promote the success of the university'. Similarly, Kim et al. (2010) state that when students' levels of OI are high, their behaviour towards the university could be changed to support the behaviour that is encouraged by the university. These authors suggest that students with a strong identification with their university will become emotionally attached to that university. They will therefore increase the 'time and effort' that they put into their work, share in the university's accomplishments and failures as if they are a part of their own and become so attached to the university that the 'university's actions will reflect on them and their actions will reflex on the university' (Kim et al., 2010, p. 14). Understanding student OI can assist university management in improving student-university relations. Students will put more effort into their work if they identify strongly with the university, which will result in better quality graduates and an increased international reputation for the university, amongst other factors. High levels of OI can also result in future donations from alumni students (Beelen, 2007).

Frenkel, Restubog and Bednall (2012) explain that employees who have a strong identification with the organisation will feel that they are a part of the organisation and, the stronger that individuals identify with a particular organisation's attributes, the more they will use the same attributes to define themselves (Dutton et al., 1994). Furthermore, a positive attitude towards an organisation and consensus with decisions made is a result of members identifying strongly with the organisation (Van Riel \& Fombrun, 2008). The same principle can be applied to students. When students identify strongly with their university, they will be more willing to wear university-sponsored clothing in public and increase positive word of mouth in their communities toward the university (Bartels, 2006).

Van Knippenberg and Sleebos (2006) explain that higher levels of OI will result in an increase in organisational values, norms and interest. This will result in a member remaining with a particular organisation for longer periods of time. This is also true for universities. Students who identify with their university are more likely to undertake their postgraduate studies at the same university (Kim et al., 2010).

\section{Demographic variables that influence organisational identification}

It is important at this stage to clarify whether demographic variables have an influence on levels of OI. As previously mentioned by Bartels (2006), individuals can identify with any particular group. Examples of such groups to which individuals can associate themselves include age, gender, race, political movements and sport teams. In this line, Chavous, Rivas, Green and Helaire (2002) explain that it is easier for individuals to identify with groups that have similar characteristics as themselves. In the university setting, firstyear students will adapt readily to their new environment when they can identify, for example, with a group of the same race (Chavous et al., 2002). Therefore:

- Hypothesis 1: race influences the level of OI amongst students.

Based on Bartels (2006) and Chavous et al.'s (2002) insights above, the researchers hypothesise that two other groups with which students can identify within a university setting include their respective faculty and campus. Therefore:

- Hypothesis 2: faculty influences the level of OI amongst students.

- Hypothesis 3: campus influences the level of OI amongst students.

According to a study conducted by Mael and Ashforth (1992), there is a positive correlation between organisational tenure and employee OI. The longer an employee stays at an organisation, the more intertwined he or she becomes in the organisation. In the same line, Rusbult and Farrell (in Maurer, 2007) state that an individual's level of OI could increase with time. Thus in a university setting, it can be hypothesised that the longer a student studies at one single university, the higher his or her OI levels will be. Therefore:

- Hypothesis 4: university tenure has an influence on the level of OI amongst students.

Maurer (2007) explains that students who live in on-campus residences have a higher possibility to identify more strongly with their particular university. The reason for this is that students who stay on the campus of their university are more likely to be involved in the activities of their university and therefore are more satisfied with their university experience. This results in high levels of identification with the university (Maurer, 2007). Therefore:

- Hypothesis 5: residence has an influence on the level of OI amongst students.

\section{Organisational identification factors}

Numerous factors influence an individual's level of OI. The following factors of OI were derived by Caboni and Eisemen (2003) and Arpan, Raney and Zivnuska (2003).

Organisational identification (renamed 'emotional attachment'): The researchers of this study renamed the first factor listed by Caboni and Eisemen (2003) (i.e. 'organisational identification'), as 'emotional attachment'. This is because of the fact that the instrument as a whole which was used by these authors measured organisational identification, yet one of the subscales in this instrument was named 'organisational identification'. The researchers thus changed the name of this subscale to 'emotional attachment' as this better represents the items in the subscale and prevents confusion.

To illustrate the relationship between OI and emotional attachment, Bartels, Peters, De Jong, Pruyn and Van der Molen (2010) state that OI is associated with an employee's 
emotional attachment to a group, rather than an affiliation of pride (Dutton et al., 1994). Cole and Bruch (2006, p. 585) agree with Bartels et al. (2010) and Dutton et al. (1994) by stating that OI 'examines the process whereby an individual's identity becomes psychologically intertwined with the organisation's identity'. Tajfel (1982) explains this emotional attachment as classical identification, which is defined as the emotional value and meaning of an individual's membership within a group and how cognitively aware such individuals are of this membership. When students have an emotional connection to the university, they will feel obligated to stay and support their current university (Kim et al., 2010). According to Bartels et al. (2010), OI decreases turnover and is therefore likely to retain students at universities.

It is made clear by Ciftciogiu (2010) that in order for identification to take place, membership is required, otherwise it can lead to inadequate socialisation and therefore the emotional connection with the organisation will not form. Hartel, Ashkanasy and Zerbe (2006) state that there are two ways in which employees can attach themselves to the organisation. Firstly, there is a social desire to be accepted by society and, secondly, there are the organisation's actions which enhance the employees' perceptions that they and their well-being are valued by the organisation (Hartel et al., 2006). From a student perspective, Sperlich and Spraul (2007) mention that it is important to engage students in order to participate actively in their education. These authors indicate that active participation of decision-making by students can increase their attachment to the organisation.

Involvement: Astin (1999, p. 518) defines student involvement as the amount of physical and psychological energy that the student devotes to the academic experience'. Astin identifies a number of factors that would influence student involvement, which will be discussed as follows. Firstly, student-faculty interaction and student involvement in student government activities have a positive effect on their involvement with the university (Astin, 1999). Students who meet with university staff members on a regular basis will have an increased sense of belonging and therefore experience an increase in their level of OI, according to Astin. This author further explains that students who participate in student governance activities have an opportunity to interact amongst their peers and make a difference in the university experience. This increases the power given to students and can give them a sense of belonging and a feeling that they matter to the student body, increasing their level of OI. However, Maurer (2007) found that psychological investment is necessary to ensure involvement, as opposed to only attending the activities.

According to Ciftciogiu (2010), student involvement and engagement are necessities for learning, with engagement, involvement and attachment all having a relationship with one another. Student engagement is defined by Natriello (in Ciftciogiu, 2010, p. 14), as taking part in the various activities that school programmes offer to students. This can relate to students' willingness to partake in regular activities at school as well, such as attending class and submitting the required work following a teacher's directions. Furthermore, student engagement can be viewed as students' sense of belongingness and attachment to their particular university (Archambault, Janosz, Fallu \& Pagani, 2009, p. 652). In Finn's (in Ciftciogiu 2010) participation-identification model of school withdrawal, lack of OI leads to withdrawal and disengagement, which, as a result, can lead to school dropout.

Perceived educational effectiveness: Clayson (2009) states that the effectiveness of teaching has become increasingly important as a result of universities wanting to ensure that they attract and retain the best students. The way in which lecturers present their lectures and the way in which they interact with their students can influence students' level of OI. Therefore students' perceptions of educational effectiveness are important to consider when measuring OI. Delaney, Johnson, Johnson and Treslan (2010) mention that students in higher education perceive their education to be effective when instructors are respectful of students, knowledgeable, approachable, engaging, communicative, organised, responsive, professional and humorous. Delaney et al. (2010) also found that these characteristics were not dependent on the method of teaching. Feldman (1976) evaluates various factors that are perceived by students to influence their educational effectiveness. Feldman's findings identify three clusters according to which students perceive educational effectiveness. These three clusters include instructor presentation of material, facilitation of learning and the regulation of learning. The cluster concerning how the lecturer presents the material is influenced by how effectively the lecturer stimulates students' interest, how enthusiastic the lecturer is about the subject and how knowledgeable the lecturer is with regard to the specific subject (Feldman, 1976). Feldman states that facilitation of learning is determined by the preparedness of the lecturer, sensitivity to students' progress and encouragement toward students. The regulation of learning is dependent on the encouragement of open discussions in class, opportunities for students to be intellectually challenged and how frequently feedback is received (Feldman, 1976).

Perceived institutional prestige: Social identification and social categorisation theories have given insight into the fact that an employee's positive perception of his or her organisation's prestige can lead to a positive self-esteem of the individual and a positive assessment of one's self-image (Ciftciogiu, 2010). Therefore, various researchers agree that the more positive the external perception of employees is, the greater the self-esteem of the employees and, as a result, the greater the employees' loyalty (Riketta, 2005; Van Knippenberg \& Sleebos, 2006).

Additionally, Cialdini et al. (1976, p. 366) state that if the members of an organisation believed that the organisation to which they belong is seen in a positive light, then these members will 'bask in the glory' of that organisation. In this 
manner, as Ciftciogiu (2010) states, individuals usually want to be a part of the best or be associated with excellence. It is said that a tertiary university will make use of this desire of students to attract them to that particular university (Ciftciogiu, 2010). Porter et al. (2011) mention that universities which are more selective will be seen as prestigious. The enhanced perceived institutional prestige will increase the students' identification, because they want to belong to that particular university (Porter et al., 2011).

University image: According to Kazoleas, Kim and Moffit (2001, p. 205), service organisations' success is highly dependable on the image they portray. This organisational image is perceived as a collection of images from the receiver's point of view, as opposed to a construct that the organisation determines and controls (Kazoleas et al., 2001). Universities as service organisations are therefore dependent on the image that they portray to students and the greater public.

In Arpan et al.'s (2003) study on university image, they view a university as an organisation. They stated that various factors influence an organisation's image and therefore make the concept of organisational image a multidimensional concept. Arpan et al. (2003) go on to list some of the factors that influence organisational image as: the size of the organisation's profitability, degree of diversification, familiarity of the organisation, perceived nature of the community, employee relations, social responsibility efforts, perceived quality of the organisation's product and services and, lastly, the intensity of its marketing campaigns.

Arpan et al. (2003, p. 99) refer to Kazoleas et al.'s (2001) study, in which they identify that students do make a comparison between universities with regard to specific attributes which include 'high quality undergraduate programmes, a faculty committed to providing quality education, and commitment to providing good services to students'. Kazoleas et al. (2001, p. 207) state that these attributes are 'separate images that contribute to the overall image of the university'. Furthermore, universities have different departments and even professors in certain subject areas that influence the image of the organisation (Kazoleas et al., 2001). Different departments lead to different images of the organisation. These authors believe that these results indicate that a university can have multiple images and sometimes these images can be in conflict with one another. It sometimes happens that a university has an overall strong image and that reputation is what attracts students to that particular university.

\section{Research design Research approach}

A mixed method approach of both qualitative and quantitative research techniques were utilised in this study, with the quantitative research being of central importance and supported by the qualitative research findings. The quantitative component of this study was of primary significance to the researchers in order to statistically measure and analyse the OI levels of the students under study. However, this could only be conducted once the qualitative research component of the study was carried out, as the qualitative feedback received served to ensure that the instrument used by Caboni and Eisemen (2003) was appropriate for the university setting in which this study was to be conducted. Additionally, the qualitative study provided the researchers with in-depth information that could be used to formulate recommendations to improve OI once the quantitative study was complete.

\section{Research method}

\section{Research participants}

The majority of students that participated in both the qualitative and quantitative components of this study had enrolled after the university had merged. However, the postgraduate students included in the study might have begun studying at this university prior to the merger occurring.

The qualitative research design was executed by means of two focus group discussions conducted at the university under study. Two focus groups were held to provide the researchers with optimal opinions from the respondents (Babbie, 2010). From Table 1, it can be seen that 18 students participated in the focus group discussions. The majority of the students were female and over half of the participants were completing their second year of studies. The focus groups assisted the researchers in determining which factors influenced the level of OI amongst students.

In terms of the quantitative research, Table 2 illustrates that although a relatively even distribution of genders was obtained, the sample was heavily weighted towards students in the 18 - 22 age group, those living off-campus, as well as Black students. A total of 603 students fully completed the online questionnaire, indicating a response rate of $2.31 \%$. For the exploratory purpose of this study, the response rate has been deemed sufficient (Maholtra, 2007).

TABLE 1: The descriptive statistics for gender and year of study of the focus group discussions.

\begin{tabular}{lllllllc}
\hline Factor & Sub-factor & \multicolumn{2}{c}{ Focus group 1 } & & \multicolumn{2}{c}{ Focus group 2 } \\
\cline { 3 - 4 } \cline { 6 - 7 } & & $\boldsymbol{n}$ & $\mathbf{\%}$ & & $\boldsymbol{n}$ & $\mathbf{\%}$ \\
\hline Gender & Male & 2 & 20 & & - & 0 \\
& Female & 8 & 80 & & 8 & 100 \\
Year of & 1styear & 1 & 10 & & - & 0 \\
Study & 2nd year & 2 & 20 & & 8 & 100 \\
& 3rd year & 3 & 30 & & - & 0 \\
& Postgraduate & 4 & 40 & & - & 0 \\
\hline Total & - & $\mathbf{1 0}$ & $\mathbf{1 0 0}$ & & $\mathbf{8}$ & $\mathbf{1 0 0}$ \\
\hline
\end{tabular}

$n$, number of participants per focus group. 
TABLE 2: The demographic profile of the quantitative research.

\begin{tabular}{|c|c|c|c|c|c|}
\hline Factor & Sub-factor & $n$ & Percentage & Mean & SD \\
\hline \multirow[t]{2}{*}{ Gender } & Male & 253 & 42 & 3.81 & 0.54 \\
\hline & Female & 350 & 58 & 3.80 & 0.57 \\
\hline \multirow[t]{4}{*}{ Age (years) } & $18-22$ & 450 & 75 & 3.82 & 0.55 \\
\hline & $23-27$ & 110 & 18 & 3.77 & 0.56 \\
\hline & $28-32$ & 26 & 4 & 3.73 & 0.58 \\
\hline & $33+$ & 17 & 3 & 3.73 & 0.67 \\
\hline \multirow{5}{*}{$\begin{array}{l}\text { Year of } \\
\text { study }\end{array}$} & First & 249 & 41 & 3.91 & 0.49 \\
\hline & Second & 179 & 30 & 3.78 & 0.58 \\
\hline & Third & 103 & 17 & 3.80 & 0.57 \\
\hline & Fourth & 31 & 5 & 3.56 & 0.61 \\
\hline & Postgraduate & 41 & 7 & 3.44 & 0.58 \\
\hline \multirow[t]{2}{*}{ Residence } & On campus & 116 & 19 & 3.96 & 0.56 \\
\hline & Off campus & 487 & 81 & 3.77 & 0.55 \\
\hline \multirow[t]{6}{*}{ Campus } & Campus 1 & 0 & 0 & 0 & 0 \\
\hline & Campus 2 & 11 & 4 & 3.73 & 0.58 \\
\hline & Campus 3 & 41 & 17 & 3.89 & 0.54 \\
\hline & Campus 4 & 33 & 13 & 3.94 & 0.64 \\
\hline & Campus 5 & 136 & 55 & 3.69 & 0.54 \\
\hline & Campus 6 & 25 & 10 & 4.12 & 0.46 \\
\hline \multirow[t]{3}{*}{ Race } & Black students & 362 & 60 & 3.96 & 0.54 \\
\hline & White students & 145 & 24 & 3.51 & 0.52 \\
\hline & $\begin{array}{l}\text { Mixed race } \\
\text { students }\end{array}$ & 96 & 16 & 3.69 & 0.47 \\
\hline \multirow[t]{7}{*}{ Faculty } & Faculty 1 & 83 & 14 & 3.86 & 0.48 \\
\hline & Faculty 2 & 224 & 37 & 3.82 & 0.59 \\
\hline & Faculty 3 & 49 & 8 & 3.64 & 0.52 \\
\hline & Faculty 4 & 58 & 10 & 3.85 & 0.61 \\
\hline & Faculty 5 & 119 & 20 & 3.86 & 0.50 \\
\hline & Faculty 6 & 19 & 3 & 3.85 & 0.59 \\
\hline & Faculty 7 & 51 & 8 & 3.36 & 0.60 \\
\hline
\end{tabular}

$n$, number of respondents per category; SD, standard deviation.

$N=603$, except for Campus, where $N=246$.

\section{Measuring instruments}

For the qualitative study, questions were asked to stimulate discussion based on the four factors that influence students' levels of OI, as identified in Caboni and Eiseman's (2003) study. These included the extent of the students' emotional attachment to the university, their perception of the university's educational effectiveness, students' perception of the university's prestige and the involvement of the students in university activities (Caboni \& Eiseman, 2003). The researchers made use of a voice recorder, with the consent of the participants, to record both focus group discussions.

The findings from the qualitative study confirmed that the instrument used by Caboni and Eiseman (2003) was appropriate for use in the quantitative component of this study. The original instrument had inconsistent items and was therefore adapted for the South African context for this study based on results obtained from the focus groups. The results from the focus group discussions indicated that university image also plays a role in the level of OI amongst students. Therefore, the researchers included a fifth factor to the instrument, namely university image. The items used for this factor were adapted from the study conducted by Arpan et al. (2003). The final factors measured in this study were thus emotional attachment (Factor 1), involvement (Factor 2), perceived educational effectiveness (Factor 3), perceived institutional prestige (Factor 4 ) and university image (Factor 5) (see Tables 3 and 4).
The items in the questionnaire were measured using a five-point Likert scale. The questionnaire consisted of two sections. The first section contained five items per factor, for a total of five factors (i.e. those listed above). The second section, demographic variables, consisted of seven categories, namely gender, age, year of study, residence, campus, race and faculty.

Cronbach coefficient alphas were used to determine the reliability of the instrument. According to Maholtra (2007), a coefficient alpha of less than 0.60 is unsatisfactory and therefore the factor is unreliable. All of the factors had a Cronbach coefficient alpha of above 0.60, therefore the reliability measures of the instrument can be deemed satisfactory. Emotional attachment had a Cronbach coefficient alpha of 0.74 , involvement 0.83 , perceived educational effectiveness 0.84 , perceived institutional prestige 0.84 and university image a score of 0.67 . Content validity was ensured by linking the instrument's content to the literature component through ensuring that the items in the instrument reflect the literature available.

\section{Research procedure}

The study was performed during an 8-month period: March 2011 to October 2011. The qualitative data were collected during May 2011 and the quantitative data during September 2011. Convenience, non-probability sampling was used for the focus group discussions. The researchers made use of structured questions and guided the discussion accordingly. The questions used in the focus group sessions were derived from the instrument used by Caboni and Eiseman (2003) for the purpose of establishing whether the questionnaire would be relevant to the university students under study, as explained previously.

In the quantitative research design, the researchers made use of a structured questionnaire which was distributed to students by means of purposive, non-probability sampling. In line with the rules pertaining to ethical clearance at the university under study, the researchers applied for ethical clearance due to the sample being comprised of students. Ethical clearance was thereafter granted. In the qualitative research sessions, the researchers read the informed consent document to the students, who had the opportunity to leave at any time if they so wished. In the quantitative study, an electronic survey method was used to collect the data. The e-mail that was sent to respondents included a consent letter and the link to the online questionnaire.

\section{Statistical analysis}

The focus group discussions were recorded, which enabled the researchers to accurately capture the qualitative results. Thereafter, the researchers explored whether any factors emerged other than the four factors suggested by Caboni and Eiseman (2003). This was achieved using content analysis, in which students' responses were grouped into themes.

Data analysis for the quantitative component of the study was conducted by using descriptive and inferential statistical 
analysis. The raw data were automatically captured in Microsoft Excel by the university's online survey tool, thus eliminating manual data capturing errors. Inferential statistics were generated by using the statistical package Statistica version 10 (2011).

T-tests were used in order to determine whether a statistically significant relationship existed between residence and OI. The use of analyses of variance (ANOVAs) enabled the researchers to determine whether there is a relationship between year of study, faculty, campus, race and residence with the level of OI amongst students. This was performed in order to successfully indicate whether these variables influence students' levels of OI.

Post-hoc Scheffé's tests were used to determine the statistical significance of differences within groups that had more than two levels, such as campus and race. Cohen's d statistic was calculated where statistically significant differences were found, to determine practical significance. A Cohen's d of greater than 0.20 and less than 0.50 is accepted as a small effect, whilst greater than 0.50 and less than 0.80 is understood as a medium effect and a score greater than 0.80 implies a large practical significance (Cohen, 1988; D. Venter, personal communication, 24 September 2011).

\section{Results \\ Qualitative research findings}

The qualitative findings from the focus group discussions were used to determine whether the factors in Caboni and Eiseman's (2003) instrument were applicable to this university. The researchers found that the students referred to university image as an additional factor to those of Caboni and Eiseman and therefore added this as a fifth factor. The qualitative findings were also used to develop recommendations to the university as to how to increase OI levels amongst students. These recommendations will be discussed in the 'Conclusion' section of this article.

\section{Students' comments on whether they are proud to be associated with the university}

The majority of students stated that they are proud to be associated with this university. Some reasons given for their pride in the university include:

- Higher educational standards compared with other South African universities.

- Diversity week (where students are encouraged to wear traditional clothing and various cultures are celebrated through song, dance and culinary experiences).

- The 'One Day Without Shoes' campaign, an annual international initiative supported by this university that encourages students to spend a day without wearing shoes to identify with those living in poverty (http:// www.onedaywithoutshoes.com).

- Support from classmates in postgraduate classes.

- Professional and approachable lecturers.

- Accessible study opportunities being made available to them.
However, not all students had consensus in this regard. Some of the reasons why students are not proud to be associated with this university include:

- Administrative burdens and bureaucracy.

- The university not being well known to international students.

- A lack of 'RAG party opportunities'. RAG stands for 'Remember and Give'. It is a non-profit organisation, which, in conjunction with the Campus Life Festival held at this university, hosts numerous activities for students in order to raise funds for charity organisations.

- A perception of inconsiderate lecturers.

- Racial issues coming to the fore between students.

\section{Factors that would increase students' levels of organisational identification}

Students stated that a higher quality of education would increase their level of OI. It was mentioned that certain faculties are known by their students for their quality. Students that study in faculties with reputations for quality might therefore identify stronger with the university than students from other faculties.

The participants agreed that recognition for their hard work will also increase their levels of identification. Students believe that the bureaucracy in administration needs to be reviewed and streamlined.

\section{Factors that would decrease students' levels of organisational identification}

The participants felt that lecturers' teaching skills do not represent their qualification and experience. Students felt that certain lecturers at this university have the necessary qualifications, but do not have the teaching skills required to pass that knowledge on to them. This leads to these students not identifying with the university. It was mentioned that certain lecturers focus so much on their own research that they are not adequately prepared for their role as lecturer. The researchers noted that this could imply that students do not understand the link between an academic's own research and his or her role as lecturer and thus might not comprehend the vital interplay between these two roles in broadening the knowledge base of students.

Some participants felt that certain lecturers are maintaining a much higher standard than other universities, therefore decreasing the students' possibilities to transfer to other universities because of their resultant low marks. It is believed by students that higher standards lead to lower results and students do not perceive these high standards as sufficient reason for giving students poor marks in relation to other universities. The researchers thus observed that students often do not grasp the benefit of high tertiary educational standards, which equip them to compete effectively in the global marketplace.

\section{Students' opinions on involvement in societies}

The participants in the focus groups agreed that involvement in societies gives them the opportunity to meet other 
students and experience different cultures. This establishes new bonds between students. Other students believed that involvement in societies gives them the opportunity to have extra responsibilities. Students also mentioned that the red tape that is involved at this university made it difficult to host activities in societies and therefore members became frustrated. This can lead to a decrease in OI.

Students' levels of identification increased with involvement in communities for practical application as part of their curriculums. Students feel motivated when they are given the opportunity to apply the skills that they learn in their studies by giving back to the community. It is therefore believed that involvement in societies will increase students' levels of OI. However, there is no society that the students under study felt appealed to them personally. Other students stated that they stay in areas that are far away from the university's campuses and therefore find it difficult to travel to the university solely to participate in extracurricular activities.

\section{Students' perceptions on why certain universities in other provinces are seen as prestigious}

Participants mentioned two Western Cape universities as being perceived to be prestigious. Reasons included that these universities are known internationally and are perceived to produce good quality graduates. Students mentioned that South African universities that have been ranked highly in relation to overseas universities have higher statuses than other South African universities. However, their quality of education is not perceived as different from that of the university under study. The students felt that individuals from the Western Cape are naturally proud to be associated with the geographical location of the universities. Individuals from the Eastern Cape do not share the same perceived status.

\section{Quantitative research results}

\section{Descriptive statistics}

Table 3 illustrates that students perceive the researched university's education standards to be effective (Factor 3) - this factor had the highest mean score of 4.27. The lowest mean is that of perceived institutional prestige (Factor 4). The students believe that the perceived institutional prestige of their university is the weakest of the five factors.

Jorgensen (2006) and D. Venter (personal communication, 24 September 2011) explained that scores from a fivepoint Likert scale can be categorised as 'low' when falling between 1.00 and 2.59, with a neutral score falling between 2.60 and 3.40 and a high score falling between 3.41 and 5.00. Emotional attachment, involvement, perceived educational effectiveness and university image all obtained high scores, according to these categories.

On the five-point Likert scale, the total level of OI for this university is 3.81 , with a standard deviation of 0.56 . The researchers have no indication from previous literature as to what level of OI can be perceived as being high or low in comparison to other universities. However, according to the statistically derived categories, a score of 3.80 is seen as a high level of OI amongst students.

\section{Analysis of variance}

Table 4 illustrates that there is a statistically significant relationship between Factor 1 and year of study, residence, campus and race, because all the $p$-values for these variables were less than the significance level of 0.01. At a significance level of less than 0.01, Factor 2 showed a statistically significant relationship with faculty, year of study, campus and race. The ANOVA showed that Factor 3

TABLE 3: The descriptive statistics for each of the five factors and Factor T.

\begin{tabular}{lccccc}
\hline $\begin{array}{l}\text { Descriptive } \\
\text { Statistic }\end{array}$ & $\begin{array}{c}\text { Factor 1: } \\
\text { Emotional attachment }\end{array}$ & $\begin{array}{c}\text { Factor 2: } \\
\text { Involvement }\end{array}$ & $\begin{array}{c}\text { Factor 3: } \\
\text { Perceived educational } \\
\text { effectiveness }\end{array}$ & $\begin{array}{c}\text { Factor 4: } \\
\text { Perceived institutional } \\
\text { prestige }\end{array}$ & $\begin{array}{c}\text { Factor 5: } \\
\text { University image } \\
\text { Total organisational } \\
\text { identification }\end{array}$ \\
\hline Mean & 3.89 & 4.00 & 4.27 & 3.00 & 3.87 \\
SD & 0.75 & 0.71 & 0.63 & 0.85 & 3.81 \\
Median & 4.00 & 4.00 & 4.40 & 3.00 & 0.59 \\
Minimum & 1.00 & 1.00 & 1.20 & 1.00 & \\
Maximum & 5.00 & 5.00 & 5.00 & 5.00 & \\
\hline
\end{tabular}

SD, standard deviation.

TABLE 4: The analysis of variance that determined the relationships between demographic variables and each of the factors.

\begin{tabular}{|c|c|c|c|c|c|c|c|c|c|c|c|c|}
\hline \multirow[t]{2}{*}{$\begin{array}{l}\text { Demographic } \\
\text { variables }\end{array}$} & \multicolumn{2}{|c|}{$\begin{array}{c}\text { Factor 1: } \\
\text { Emotional attachment }\end{array}$} & \multicolumn{2}{|c|}{$\begin{array}{c}\text { Factor 2: } \\
\text { Involvement }\end{array}$} & \multicolumn{2}{|c|}{$\begin{array}{c}\text { Factor 3: } \\
\begin{array}{c}\text { Perceived educational } \\
\text { effectiveness }\end{array}\end{array}$} & \multicolumn{2}{|c|}{$\begin{array}{c}\text { Factor 4: } \\
\text { Perceived institutional } \\
\text { prestige }\end{array}$} & \multicolumn{2}{|c|}{$\begin{array}{c}\text { Factor 5: } \\
\text { University image }\end{array}$} & \multicolumn{2}{|c|}{$\begin{array}{c}\text { Factor T: } \\
\text { Total organisational } \\
\text { identification }\end{array}$} \\
\hline & $F$ & $p$ & $F$ & $p$ & $F$ & $p$ & $F$ & $p$ & $F$ & $p$ & $F$ & $p$ \\
\hline Gender & 0.22 & 0.636 & 2.66 & 0.1036 & 1.10 & 0.2930 & 5.98 & 0.0147 & 0.62 & 0.4301 & 0.07 & 0.7902 \\
\hline Age & 1.25 & 0.292 & 0.65 & 0.5837 & 1.36 & 0.2550 & 1.19 & 0.3146 & 1.13 & 0.3365 & 0.67 & 0.5729 \\
\hline Faculty & 2.04 & 0.059 & 3.35 & $0.0029 * *$ & 1.30 & 0.2541 & 2.28 & 0.0351 & 2.55 & $0.0192^{*}$ & 2.00 & 0.0631 \\
\hline Year of study & 60.31 & $0.000 * *$ & 5.23 & $0.0000^{* *}$ & 11.63 & $0.0000 * *$ & 4.45 & $0.0015^{* *}$ & 6.91 & $0.0000 * *$ & 9.28 & $0.0000 * *$ \\
\hline Campus & 3.46 & $0.009 * *$ & 3.63 & $0.0069 * *$ & 3.73 & $0.0058 * *$ & 2.11 & 0.0808 & 6.31 & $0.0001 * *$ & 4.29 & $0.0023 * *$ \\
\hline Race & 30.99 & $0.000 * *$ & 12.65 & $0.0000 * *$ & 16.63 & $0.0000 * *$ & 45.55 & $0.0000 * *$ & 23.55 & $0.0000 * *$ & 40.33 & $0.0000 * *$ \\
\hline
\end{tabular}

$F$, variance of the group means; $p$, level of significance.

$N=603$.
$*, p<0.05 ; * *, p<0.01$. 
had a statistically significant relationship with year of study, residence, campus and race at a significance level of less than 0.01 . Factor 4 had a statistically significant relationship with year of study, residence and race at a significance level of less than 0.01. At a significance level of less than 0.01, Factor 5 had a statistically significant relationship with year of study, campus and race. At a significance level of less than 0.05 , Factor 5 had a statistically significant relationship with faculty.

For the purpose of this study, the research only focused on the demographic variables that influence the total OI of the students investigated, as this relates to the set of hypotheses of the study. At a significance level of less than 0.01, a statistically significant relationship existed between Factor $\mathrm{T}$ (total OI) and year of study, residence, campus and race. This implied that only year of study, residence, campus and race had an influence on students' levels of OI. These demographic variables are discussed in more detail in the next section.

\section{Discussion of hypotheses}

Hypothesis 1: Owing to the small number of respondents from Indian and Asian racial groups, the researchers made the decision to include these groups in the 'Mixed race' group. Table 2 indicates that Black students had the highest mean score of 3.96 and a standard deviation (SD) score of 0.54. This implied that Black students have higher levels of OI than the Mixed race group and White students.

In Table 4, it is illustrated that at a significance level of less than 0.01 , a statistically significant relationship existed between race and OI. Scheffé's tests were conducted because the ANOVA identified significant differences for race and OI. According to Table 5, the Cohen's d for Black students and White students had a large practically significant difference of 0.84, whilst Black students and Mixed race students had a medium practically significant difference of 0.50 and White students and Mixed race students had a small practically significant difference of 0.38 . Thus, because race has an influence on students' level of OI, Hypothesis 1 is accepted.
Hypothesis 2: Table 4 indicates that there was no statistically significant relationship between faculty and students' level of OI. This implied that faculty has no influence on the level of OI amongst students. Therefore, Hypothesis 2 is rejected.

Hypothesis 3: From Table 2, it is evident that Campus 6 has the highest level of OI amongst students because of its mean score of 4.12. No responses were gained from Campus 1.

Table 4 indicates that at a significance level of less than 0.01 , a statistically significant relationship existed between Campus and students' level of OI. According to Table 6, a large practically significant difference existed between Campus 5 and Campus 6 because the Cohen's d (0.81) was greater than 0.80. A medium practical significance existed between Campus 2 and Campus 6, because the Cohen's d value (0.78) was greater than 0.50 and less than 0.80 . All other relationships between the various campuses were found to have had a small practical significance. Owing to the statistically and practically significant relationship between Campus and students' levels of OI, Hypothesis 3 is accepted.

Hypothesis 4: University tenure refers to the length of time a student spends studying at one particular university. Table 2 shows that the mean scores decrease as a student continues studying at this university. This implied that the relationship between OI and year of study decreased the longer a student studies. A reason for this can be because of the merger of this university, as previously mentioned. Postgraduate students who study at this university could still be associating themselves with one of the institutions that existed prior to the merger rather than with the recently merged university, because they began studying here before the merger took place.

A statistically significant relationship existed between students' year of study and OI, because the $p$-value was less than a significance level of 0.01 (Table 4). According to Table 7 , there was a large practically significant difference between first-year students' levels of OI and postgraduate students' levels of OI, because Cohen's d was larger than 0.80. A medium practically significance difference existed between first-year students and fourth-year students,

TABLE 5: The practical significance of the impact of race on organisational identification.

\begin{tabular}{|c|c|c|c|c|c|c|}
\hline Race & $n$ & Mean & SD & Scheffé's p & Cohen's d & Interpretation \\
\hline Black students & 362 & 3.96 & 0.54 & 0.000000 & 0.84 & Large \\
\hline White students & 145 & 3.51 & 0.52 & & & \\
\hline Black students & 362 & 3.96 & 0.54 & 0.000095 & 0.50 & Medium \\
\hline Mixed race students & 96 & 3.69 & 0.47 & & & \\
\hline White students & 145 & 3.51 & 0.52 & 0.184955 & 0.38 & Small \\
\hline Mixed race students & 96 & 3.69 & 0.47 & & & \\
\hline
\end{tabular}

$n$, number of respondents per racial category; SD, standard deviation.

TABLE 6: The practical significance of the impact of campus on organisational identification.

\begin{tabular}{llllll}
\hline Campus & $\boldsymbol{n}$ & Mean & SD & Scheffé's p & Cohen's d \\
\hline Campus 2 & 11 & 3.73 & 0.58 & 0.540811 & \\
Campus 6 & 25 & 4.12 & 0.46 & & Interpretation \\
Campus 5 & 136 & 3.69 & 0.54 & 0.013028 & 0.81 \\
Campus 6 & 25 & 4.12 & 0.46 & & Large \\
\hline
\end{tabular}

$n$, number of respondents per campus; SD, standard deviation. 
second-year students and postgraduate students, as well as third-year students and postgraduate students' levels of OI, with a Cohen's d of between 0.20 and 0.50. All of the other combinations held a small practically significant difference. Students' levels of OI thus decrease with university tenure and, for this reason, Hypothesis 4 is accepted.

Hypothesis 5: The mean score for both on-campus and off-campus residents was high according to the categories mentioned previously, with a mean score of 3.96 and 3.77, respectively (Table 2). According to the ANOVA analysis in Table 4, a statistically significant relationship existed between OI and residence because the $p$-value was less than 0.01 . Cohen's d in Table 8 indicated a small practically significant difference of 0.34 . Thus, residence has an influence on OI and Hypothesis 5 is accepted.

\section{Ethical considerations}

The researchers were required to process the proposal through the necessary ethical clearance procedure required by the tertiary institution under study. An ethics clearance number (H 2011 BUS IPH 12) was received from the institution's Research Ethics Committee (Human) in order to go ahead with the study.

\section{Potential benefits and hazards}

The measurement instrument utilised in this study posed no risk or danger to participating respondents. The data collected from the empirical study were stored safely and only the researchers had the required access to the data. The respondents can only benefit from this study if the tertiary institution implements the study's recommendations.

\section{Recruitment procedure}

It was emphasised to all respondents and participants in both phases of the empirical investigation that their responses would be kept confidential. The researchers also ensured that all respondents were aware that participation was voluntarily. Respondents could withdraw from the research at any stage if they so wished. Respondents were recruited for both empirical methods through the use of electronic invitation. In the case of the qualitative study, respondents were electronically invited to attend the focus group discussion and it was made clear that the discussions were voluntary. The electronic invitation to partake in the survey included a description of the study with a hyperlink that would provided participants access to the questionnaire.

\section{Informed consent}

Students were introduced to the topic of organisational identification and the purpose of the study. The researchers clearly outlined the objectives of the study and encouraged respondents to ask questions when they were unsure or concerned.

\section{Data protection}

The electronic notes and recordings of the focus group discussions, as well as the responses of the questionnaires, which were electronically captured, were stored in passwordprotected files accessible only to the researchers.

\section{Trustworthiness Reliability}

Focus group discussion reliability was ensured by using the same group facilitator for both the discussions, as well as the use of structured questions in the discussions. The responses to the electronic questionnaire were kept confidential and respondents were able to answer the questionnaire in their own time, thus eliminating bias. Additionally, reliability measures such as Cronbach alpha, item to total correlation and inter-item correlations determined the questionnaire to be reliable.

\section{Validity}

The validity of the empirical study was improved by adapting and applying the empirical method outlined for an

TABLE 7: The practical significance of the impact of year of study on organisational identification.

\begin{tabular}{|c|c|c|c|c|c|c|}
\hline Year of study & $n$ & Mean & SD & Sheffè's p & Cohen's d & Interpretation \\
\hline First & 249 & 3.91 & 0.49 & 0.093103 & 0.70 & Medium \\
\hline Fourth & 31 & 3.56 & 0.61 & & & \\
\hline First & 249 & 3.91 & 0.49 & 0.002809 & 0.93 & Large \\
\hline Postgraduate & 41 & 3.44 & 0.58 & & & \\
\hline Second & 179 & 3.78 & 0.58 & 0.039749 & 0.59 & Medium \\
\hline Postgraduate & 41 & 3.44 & 0.58 & & & \\
\hline Third & 103 & 3.80 & 0.57 & 0.112746 & 0.63 & Medium \\
\hline Postgraduate & 41 & 3.44 & 0.58 & & & \\
\hline
\end{tabular}

$n$, number of respondents per year of study; SD, standard deviation.

TABLE 8: The practical significance of the impact of residence on organisational identification.

\begin{tabular}{llllll}
\hline Residence & $\boldsymbol{n}$ & Mean & SD & Scheffé's p & Cohen's d \\
\hline On campus & 116 & 3.96 & 0.56 & 0.00 & 0.34 \\
Off campus & 487 & 3.77 & 0.55 & Small & \\
\hline
\end{tabular}

$n$, number of respondents per residential status; SD, standard deviation. 
instrument that had already been used by previous authors. Face validity was ensured by the instrument being acceptable to an expert in the field of OI. Additionally, content validity was ensured by linking the instrument content to the literature. Valid interpretations of statistical results were obtained by utilising standardised techniques.

\section{Discussion}

The objective of the study was to determine the level of OI amongst students at a post-merged university and establish which demographic factors particularly influence OI. The study holds importance because the OI level of students at a post-merged university might be low because they might not yet identify with the values of such a university. To the researchers' knowledge, such research has not been undertaken in a post-merged university context. Therefore, this research contributes to the current body of knowledge concerning OI because a high level of OI was found amongst the students at this post-merged university. Students' race, campus, university tenure and residence furthermore have an influence on students' level of OI.

\section{Outline of the results}

According to Bartels (2006), identification can occur amongst different groups such as age, gender and race. Hypothesis 1 was accepted as race does influence the level of OI amongst students. However, age and gender had no influence on the level of OI amongst the students investigated. Identification therefore did not occur in all group situations. It was indicated that Black students have a higher level of OI than Mixed race students and White students, whilst White students have the lowest level of OI. This was supported by the qualitative research study, as the majority of the Black student respondents indicated that they are proud to be associated with this university. A probable reason for this relationship can be because the on-campus residents are more culturally homogeneous. Ashforth and Mael (1989) agree by stating that members of a group identify with groups that have similar values as to what they have. Therefore it is likely that members of the same race will identify more easily with each other (Chavous et al., 2002).

Hypotheses 2 and 3 also emulated from Bartels' (2006) view that OI can differ amongst different groups. However, Hypothesis 2 was rejected as faculty had no influence on the level of OI amongst students. Hypothesis 3 was accepted as a practically significant relationship was found between campus and students' levels of OI. This implies that the campus on which students study influences their levels of OI, but not the particular faculty in which they study. One possible reason for the higher level of OI amongst Campus 6 students may be that the majority of students enrolled at Campus 6 are Black students. Campus 6 is therefore a more racially homogenous group, which implies that they will identify more easily with each other and the campus. The fact that OI differed across campuses could also indicate that the university under study must work towards unifying the various geographical campuses through continuing to emphasise the core values of the university.

According to Maurer (2007), employee's OI will increase with organisational tenure. Thus, the researchers' fourth hypothesis was that students' levels of OI would be expected to increase with university tenure. However, the opposite was found to be true for the students investigated in this study, as the findings indicated that OI decreases with university tenure. The students who are at postgraduate level may associate themselves with the university prior to the merger, rather than the 'new' post-merged university. Another reason for the decrease in OI can be the students' experiences with the university and its activities. In the focus group discussions, the postgraduate students were those students who complained the most about this university. These students might realise the university's faults after four to five years there, as they are given more autonomy in their decision-making and come into more frequent contact with university policies and procedures.

Hypothesis 5 was accepted as a practically significant relationship between residence and OI was found. This relationship was expected, as students who stay on campus have increasingly more opportunities to participate in university activities and are encouraged to develop a special bond with fellow residence students and the university. This is confirmed by Astin (1999), who states that one of the factors that could influence student involvement is residence. A possible reason for this is that for the majority of the year, this university is their home. As previously mentioned in the literature review, student involvement is 'the amount of physical and psychological energy that the student devotes to the academic experience' (Astin, 1999, p. 518). By staying on campus, students spend the majority of their 'energy' on campus activities. This increases their involvement in the university and therefore can influence their level of OI.

The qualitative and quantitative results contained both similarities and contradictions. In terms of similarities, students stated in the focus group discussions that they do not perceive this university to be prestigious. In line with this, perceived institutional prestige (Factor 4) scored the lowest, with a mean score of 3.00. The qualitative results agreed that students were not satisfied with the reputation of the university. They felt that the university does not advertise their accomplishments nationally and this is the reason why the university is not as well-known as it could be. This indicates that students' perceptions of the university reputation are based on outsiders' perceptions of the university. Lievens, Van Hoye and Anseel (2007) state that individuals' perceptions of an institution, to some extent, can be influenced by outsiders' opinions. Another similarity is that postgraduate students in the qualitative research indicated that their level of OI has decreased as they stayed at the university under study. This was confirmed by the quantitative results. Despite the fact that both the qualitative and quantitative research indicated that OI decreased with 
university tenure, the literature review on the other hand revealed that the opposite would be true, namely that university tenure will increase students' levels of OI (Rusbult \& Farrell in Maurer, 2007).

The quantitative and qualitative research results contradicted each other with regard to perceived educational effectiveness and involvement in university activities. The quantitative results indicated that students perceived the educational effectiveness of the university to be high, with a mean score of 4.27. However, students who participated in the focus groups stated that they do not believe the level of education received is on the same standard as other South African universities and that the lecturers' abilities to teach are not at their desired standard. Factor 2 (involvement) scored a mean of 4.00. Clearly these results indicate that the students feel that they are participating in the various activities that the university offers. However, in the qualitative study, the students indicated that there are not enough activities to their liking and therefore they do not partake in the university's activities. These contradictions in findings can be ascribed to the fact that the qualitative study only represented a small sample of respondents, providing the researchers with limited opinions.

\section{Practical implications}

The fact that the level of OI amongst the students investigated is high (with a score of 3.81) is against the expectations of the researchers, who expected to find that students are in the early stages of developing a stronger identification with the postmerged university under study. Clearly, these students are identifying strongly with the university already. However, this does not correlate with the results from the qualitative study, as the majority of students who participated in the qualitative research stated that they do not identify with this university.

The researchers recommend that because race, campus, university tenure and residence influence students' levels of OI, this university should investigate implementing action plans to address the impact of these demographic variables, in order to employ effective interventions that will increase students' levels of OI.

The students that participated in the qualitative research study suggested that they would enjoy more activities in which they can take part on a social capacity. Some of the examples given by the students included diversity programmes where they can learn from one another, social responsibility projects and more RAG parties. However, the researchers noticed that all of the examples given by the students were activities that would be considered fun and that would not expect students to step out of their comfort zones. For example, they would rather go without shoes for one day in support of poverty than go to poor communities to provide practical assistance to those in need.

The lack of sufficient accommodation for students on campus makes it unattractive for students to apply to stay on campus. The violent activities and the rumours about what happens in residences contribute to students not applying to stay on campus. The management of this university needs to improve the conditions on campus and market on-campus residences to other races, as the majority of residence students are Black. Safety is another concern for most students. The on-campus residences provided by this university are not perceived to be safe by the respondents under study. If management were to address these cultural and safety issues, they could enhance the level of OI for students living on campus. Management should have equal distribution of races in oncampus residences.

Students' levels of OI at this university decrease with university tenure, so management needs to ensure a stronger identification with students who have been studying there for longer periods of time. The management of the university under study can enhance this by ensuring that they deliver quality and accredited courses on a postgraduate level. They should host more prestigious functions for these students, for example formal reward evenings. Postgraduate students are primarily responsible for upholding the reputation of this university in the workplace. If their identification decreases as they continue studying, then they will portray the lack of loyalty to this university and this will subsequently result in a decrease of the reputation of the university. Postgraduate students are also those students who conduct research and, for this reason, if this university's management focuses on improving these students' levels of OI, they may be more willing to build the reputation of the university, especially internationally. Additionally, universities should ensure that accredited courses of a high quality be offered that would be internationally recognised. The university should consistently focus on building a reputation of excellence, as well as ensure that administration becomes less bureaucratic and that qualified lecturers are appointed to instil the values of the university.

\section{Limitations of the study}

Owing to the fact that OI changes over time and this study was conducted within a 1-year time period, it can be noted that the results of this study merely provide insight into the levels of OI at this university at a specific point in time. This study is also only applicable to students from an Eastern Cape university and thus cannot necessarily be generalised to all universities in South Africa.

In the qualitative research, it was difficult to encourage students to participate in the focus group sessions. Although these students were diverse in terms of race and gender, they were all from the same campus and mostly from the same faculty. The qualitative findings therefore cannot be generalised to all university students. However, the qualitative findings were useful in achieving the aim of the qualitative component of this study, as the findings assisted the researchers in establishing the appropriateness of the instrument used in the quantitative component of the study.

Upon designing the questionnaire, one of the campuses was incorrectly omitted and the questionnaire was sent out to respondents with this error. This error was rectified 
by including the sixth campus as soon as possible after the questionnaire was sent out to the respondents. Therefore, the first 357 questionnaires could not be used for the analysis of the OI levels amongst the different campuses. The researchers also had no respondents from one campus in particular. When reading these results, the reader should bear these limitations in mind.

\section{Implications for future research}

In the literature review, it was stated by Kim et al. (2010) that students who have a high level of OI will increase the effort and time that they put into their studies. This should be investigated empirically. Van Knippenberg and Sleebos (2006) state that when strong levels of identification are experienced by employees then it is likely that they redefine themselves according to those particular organisations' values. The researchers recommend that a study be conducted on whether this is true in a university context; that is, whether students will redefine their values according to those of their university, if they experience high levels of OI.

Future research can be conducted into those factors that influence students' levels of OI, in order to determine what specific factors influence the relationship between race, campus, university tenure, residence and the overall level of OI. For example, because the OI level of students on campuses is most likely influenced by the extent to which the campus is culturally homogeneous, this implies that culture is a factor that influences the level of OI in students. Thus, variables such as the influence of culture on the level of OI amongst students, as well as the role of race in influencing the level of OI, should be investigated in more detail. The relationship between the five factors should be explored, to determine whether a correlation exists between these factors. Additionally, it has already been stated that few studies have been conducted on the influences of OI on university students. Future research should thus also attempt to investigate solutions to address low levels of OI amongst university students and how to effectively manage the levels of OI amongst these students. The researchers believe that it will be insightful to understand how students' levels of OI in this study compare to other students' levels of OI amongst other major South African universities. A similar study should thus be conducted to investigate the levels of OI amongst South African university students and how they compare to one another.

\section{Conclusion}

The aim of this study was to determine the level of OI amongst students at a post-merged university in South Africa. It was found that students' levels of OI are influenced by race, campus, university tenure and whether they stay on or off campus. Students at this university do believe that the university is trying to change for the better. Change and flexibility is indeed needed to ensure that the university achieves its vision; however, this change will be a longterm process and a university has to be unified in order for successful change to occur. OI can assist in increasing the unification of a student body.

There are various benefits of ensuring that high levels of OI are achieved amongst university students. These benefits include support behaviour from students in the future (Kim et al., 2010), for example, through financial support in the form of donations from alumni students (Caboni \& Eiseman, 2003). Furthermore, students will increase their 'time and effort' that they put into their work and will feel the university's accomplishments and failures as if their own, with the university's actions being projected onto their own lives (Kim et al., 2010). OI can thus be used to influence students' behaviour such that they act in the best interest of the university (Kim et al., 2010).

Organisational identity can also assist universities to attract and retain students to ensure that they produce high quality graduates. Students can become committed to the university through strong levels of OI. Committed and loyal students can enhance the reputation of the university. Therefore, it is important for universities to consider the implications of having students with high levels of OI, as this can be beneficial through building a university that has an international reputation (Kim et al., 2010).

From a tertiary educational perspective, universities are faced with numerous challenges, for example to motivate and engage students in order to graduate successfully. OI principles have proved to be an effective way in which these challenges can be addressed. Thus, in order for a university to become cutting edge, it is recommended that they consider the implications of OI and how to effectively improve such levels within their student body.

\section{Acknowledgements}

The researchers extend their heartfelt gratitude to the students who were involved in the study, for their time and effort put into focus group sessions and questionnaire completion. Furthermore, the researchers are grateful to the university involved in the study, as well as for the ethics clearance that was granted by its Research Ethics Committee (Human) that allowed the research to take place.

\section{Competing interests}

The authors declare that they have no financial or personal relationships which may have inappropriately influenced them in writing this article.

\section{Authors' contributions}

N.B. (Nelson Mandela Metropolitan University) completed this research for her Honours treatise in partial fulfilment of her BCom Honours degree in Industrial and Organisational Psychology. M.R. (Nelson Mandela Metropolitan University) was her primary supervisor, with R.J.S. (Nelson Mandela Metropolitan University) providing co-supervision. N.B. 
was responsible for the research, compiling the literature review and conducting the research amongst the university students. M.R. and R.J.S. assisted with the resultant data analysis, discussion of results, overall editing and co-writing of this manuscript.

\section{References}

Albert, S., Ashforth, B.E., \& Dutton, J.E. (2000). Organisational identity and identification Charting new waters and building new bridges. Academy of Management Review, 25(1), 13-17. http://dx.doi.org/10.5465/AMR.2000.2791600

Archambault, I, Janosz, M., Fallu, J.S., \& Pagani, L.S. (2009). Student engagement and its relationship with early high school dropout. Journal of Adolescence, 32, 651-670. http://dx.doi.org/10.1016/j.adolescence.2008.06.007, PMid:18708246

Arpan, L.M., Raney, A.A., \& Zivnuska, S. (2003). A cognitive approach to understanding university image. Corporate Communications: An International Journal, 8(2), 97-113. http://dx.doi.org/10.1108/1356328031047535

Ashforth, B.E., \& Mael, F.A. (1989). Social identity theory and the organization. Academy of Management Review, 35, 232-344.

Astin, A.W. (1999). Student involvement: A developmental theory for higher education. Journal of College Student Development, 40(5), 518-529.

Babbie, E. (2010). The practice of social research. (12th edn.). Melbourne: Wadswoth Cengage Learning.

Bartels, J. (2006). Organizational identification and communication: Employees evaluation of internal communication and its effects on identification at differen organisational levels. Unpublished masters thesis, University of Twente, the Netherlands.

Bartels, J., Peters, O., De Jong, M., Pruyn, A., \& Van der Molen, M. (2010) Horizontal and vertical communication as determents of professional and organisational identification. Personnel Review, 39(2), 210-226. http://dx.doi. org/10.1108/00483481011017426

Beelen, P. (2007). Organisational and professional identification: A social identity study of a post merger South African university. Unpublished masters thesis, University of Twente, the Netherlands.

Bloom, D., Canning, D., \& Chan, K. (2005). Higher education and economic development in Africa. Retrieved May 13, 2011, from http://siteresources.worldbank.org/ EDUCATION/Resource/2782001099079877269/ 5476641099079956815/Highe Ed_Econ Growth_Africa.pdf

Caboni, T.C., \& Eiseman, J. (2003, November). Ol and the voluntary support of higher education. Paper presented at the annual meeting of the Association for the Study of Higher Education, Portland. PMid:14611171

Cohen, J. (1988). Statistical power analysis for the behavioural science. (2nd edn.). Hillside: Erlbaum.

Cole, M.S., \& Bruch, H. (2006). Organizational identity strength, identification and commitment and their relationships to turnover intentions: Does organizational
hierarchy matter? Journal of Organisational behaviour, 27, 585-605.

Chavous, T., Rivas, D., Green, L., \& Helaire, L. (2002). Role of student background perception of ethnic fit, and racial identification in the academic adjustment of African American students at a predominantly white university. Journal of Black Psychology, 28(3), 234-260.

Cialdini, R.B., Borden, R.J., Thorne, A., Walker, M.R., Freeman, S., \& Sloan, L.R. (1976) Basking in reflected glory: Three football field studies. Journal of Personality and Social Psychology, 34(3), 366-375.

Ciftciogiu, A. (2010). The relationship between perceived external prestige and turnover intention: An empirical investigation. Corporate Reputation Review, 13(4), 248-263. http://dx.doi.org/10.1057/crr.2010.22

Clayson, E.D. (2009). Student evaluation of teaching: Are they related to what students learn: A meta-analysis and review of the literature. Journal of Marketing Education, 31(1), 16-30. http://dx.doi.org/10.1177/0273475308324086

Delaney, J., Johnson, A., Johnson, T., \& Treslan, D. (2010, August). Students perceptions of effective teaching in higher education. Paper presented at the 26th Annual Conference on Distance Teaching \& Learning. Madison, Wisconsin.
Dutton, J.E., Dukerich, J.M., \& Harquail, C.V. (1994). Organisational images and member identification. Administrative Science Quarterly, 39, 239-263. http:// dx.doi.org/10.2307/2393235

Feldman, K.A. (1976). The superior college teacher from the students' view. Research in Higher Education, 5, 243-288. http://dx.doi.org/10.1007/BF00991967

Foreman, P., \& Whetten, D.A. (2002). Members' identification with multiple-identity organisations. Organizational Science, 13(6), 618-635. http://dx.doi.org/10.1287/ orsc.13.6.618.493

Frenkel, S., Restubog, S.L.D., \& Bednall, T. (2012). How employee perceptions of HR policy and practice influence discretionary work effort and co-worker assistance: Evidence from two organisations. The International Journal of Human Resource Management, 23, 1-18.

Griesel, H., \& Parker, B. (2009). Graduate attributes: A baseline study on South African graduates from the perspective of employers. Retrieved May 13, 2011, from http://www.saqa.org.za/docs/pubs/general/graduate_attributes.pdf

Hartel, C.E.J., Ashkanasy, N.M., \& Zerbe, W.J. (2006). Individual and organisational perspectives on emotional management and display. Retrieved May 18, 2011 from http://espace.library.uq.edu.au/eserv.php?pid=UQ:13598\&dsID=Zerbe Ashkanasy_Hartel_Overview_ROEIO_2ndEd.pdf

Jorgensen, L.L. (2006). Rural high school principals' perception of organisational changes needed to retain rural teachers in North Dakota. Ann Arbor: UMI Dissertation Publishing.

Kazoleas, D., Kim, Y., \& Moffit, M.A. (2001). University image: A case study. Corporate Communications: An International Journal, 6(4), 205-216. http://dx.doi. org/10.1108/EUM0000000006148

Kim, T., Chang, K., \& Ko, K.J. (2010). Determinants of organisational identification and supportive intentions. Journal of Marketing Management, 26(6), 413-427. http:// dx.doi.org/10.1080/02672570903485022

Lievens, F., Van Hoye, G., \& Anseel, F. (2007). Organisational identity and employe image: Towards a unifying framework. British Journal of Management, 18, 45-59. http://dx.doi.org/10.1111/j.1467-8551.2007.00525.x

Mael, F., \& Ashforth, B.E. (1992). Alumni and their alma mater: A partial test of reformulated model of organizational identification. Journal of Organizational Behaviour, 13, 103-123. http://dx.doi.org/10.1002/job.4030130202

Maholtra, N.K. (2007). Marketing research: An applied orientation. (5th edn.). Upper Saddle River: Pearson.

Maurer, S. (2007). The relationship between college student involvement, investment and satisfaction. Unpublished Master's dissertation, Hanover College, Indiana.

Porter, T., Hartman, K., \& Johnson, J.S. (2011). Books and balls: Antecedents and outcomes of college identification. Research in Higher Education Journal, 14, $1-14$

Reger, R.K., Gustafson, L.T., Demarie, S.M., \& Mullane, J.V. (1994). Reframing the organisation: Why implementing total quality is easier said than done. Academy of Management, 19(3), 565-584.

Riketta, M. (2005). Organisational identification: A meta-analysis. Journal of Vocationa Behaviour, 66, 358-384. http://dx.doi.org/10.1016/j.jvb.2004.05.005

Sperlich, A., \& Spraul, K. (2007). Students as active partners: Higher education management in Germany. The Innovation Journal: The Public Sector Innovation Journal, 12(3), 1-19.

Statistica version 10 [Computer software] (2011). Tulsa: Statsoft, Inc. Retrieved April 15, 2011, from http://statistica.software.informer.com/10.0/

Tajfel, H. (1982). Social psychology of intergroup relations. Annual Review of Psychology, 33, 1-39. http://dx.doi.org/10.1146/annurev.ps.33.020182.000245

Tajfel, H., \& Turner, J. (1979). An integrative theory of intergroup conflict. In W.G. Austin \& S. Worchel (Eds.), The social psychology of intergroup relations, (pp. 33-47). Monterey: Brooks/Cole Publishing Company.

Taylor, S. (2010). Resourcing and talent management. (5th edn.). London: Charted Institute of Personnel and Development.

Van Knippenberg, D., \& Sleebos, E. (2006). Ol versus organisational commitment: Selfdefinition, social exchange, and attitudes. Journal of Organisational Behaviour, 27, 571-584. http://dx.doi.org/10.1002/job.359

Van Riel, C., \& Fombrun, C. (2008). The essentials of corporate communication: Experimental approach. London: Rutledge.

Winn, R.C., \& Green, R.S. (1998). Applying total quality management to the educational process. International Journal of Engineering Education, 14(1), 24-29. 